\title{
Changes in plasma concentrations of arginine vasotocin after intrauterine injections of prostaglandin $F-2 \alpha$ and acetylcholine at various times during the oviposition cycle of the domestic hen (Gallus domesticus)
}

\author{
K. Shimada*, N. Saito*, K. Itogawa* and T. I. Koike† \\ *Department of Animal Physiology, Faculty of Agriculture, Nagoya University, Chikusa, \\ Nagoya 464, Japan and $\dagger$ Department of Physiology and Biophysics, University of Arkansas \\ for Medical Sciences, 4301 West Markham Street, Little Rock, Arkansas 72205 U.S.A.
}

\begin{abstract}
Summary. Prostaglandin F-2 $\alpha$ (PGF- $2 \alpha, 1 \mu \mathrm{g})$ and acetylcholine $(10 \mathrm{mg})$ were injected into the uterus of chickens $23,21,16,8$ or $4 \mathrm{~h}$ before expected oviposition. Plasma concentrations of immunoreactive arginine vasotocin and PGF were measured in relation to the time of administration of PGF- $2 \alpha$ or acetylcholine or to the premature oviposition that was induced. PGF- $2 \alpha$ or acetylcholine administration caused premature oviposition and a marked increase in plasma arginine vasotocin levels only when an egg was present in the uterus. Changes in plasma PGF concentrations were not observed. After premature oviposition was induced, plasma values of PGF and arginine vasotocin increased at the expected time of oviposition. Manual stimulation of the uterus $4 \mathrm{~h}$ after oviposition also stimulated arginine vasotocin release. During spontaneous oviposition, a rise in plasma PGF concentration preceded increases in uterine contractility and plasma arginine vasotocin concentration. These results suggest that PGF may stimulate uterine contractility which in turn causes the release of arginine vasotocin to provide an additional contractile stimulus during oviposition.
\end{abstract}

\section{Introduction}

A transient increase in plasma arginine vasotocin concentration occurs at the time of oviposition in laying hens (Sturkie \& Lin, 1966; Niezgoda et al., 1973; Arad \& Skadhauge, 1984; Nouwen et al., 1984; Tanaka et al., 1984; Shimada et al., 1986) concurrent with a reduction in the content of vasotocin-like substance in the neurohypophysis (Tanaka \& Nakajo, 1962). The mechanism that causes the release of arginine vasotocin during oviposition is not clear. Electrical stimulation of the preoptic region of the hypothalamus causes premature oviposition in hens (Opel, 1964), suggesting that the neurohypophysis is functionally related to the increase in uterine contractility which occurs at this time. Removal of ovarian follicles delays oviposition (Rothchild \& Fraps, 1944; Tanaka \& Nakada, 1974; Shimada, 1981), indicating that the ovary may provide a signal which, directly or indirectly, causes an increase in uterine contractility. Our previous study demonstrated a simultaneous increase in plasma arginine vasotocin and uterine contractility when premature oviposition is induced by the intrauterine administration of prostaglandin F-2 $\alpha$ (PGF-2 $\alpha$ ) $2 \mathrm{~h}$ before a predicted oviposition (Shimada et al., 1986). On the other hand, Sturkie \& Lin (1966) reported that neither contractions of the oviduct nor premature oviposition induced by acetylcholine causes release of arginine vasotocin.

Uterine muscle, removed at different times during the oviposition cycle, exhibits similar contractile responses to arginine vasotocin in vitro (Olson et al., 1978), but the ability of arginine vasotocin to induce oviposition is greater when it is administered closer to the predicted time of 
oviposition (Rzasa \& Ewy, 1970). This suggests that the sensitivity of the contractile responses of the uterus to arginine vasotocin in vivo changes during the oviposition cycle. The present study was conducted to investigate changes in plasma concentrations of arginine vasotocin after injections of PGF-2 $\alpha$ and acetylcholine at various times during the oviposition cycle. In addition, uterine contractility and plasma concentrations of arginine vasotocin and PGF were measured simultaneously in relation to spontaneous and induced oviposition to determine their temporal relationships.

\section{Materials and Methods}

Animals. Crossbred laying hens ( $8-12$ months, $2 \cdot 1-2 \cdot 5 \mathrm{~kg})$ were individually caged and maintained in a light cycle of $14 \mathrm{~h}$ light $(11: 00-01: 00 \mathrm{~h})$ and $10 \mathrm{~h}$ dark, and were fed and watered ad libitum. The time of oviposition was recorded daily as described previously (Shimada \& Asai, 1978). Hens that laid regular sequences of 5 eggs or more were selected for the experiment. Hens were implanted with chronic bipolar electrodes on the smooth muscle of the caudal uterus (shell gland) for measurement of electromyographic (EMG) activity as an index of uterine contractility (Shimada, 1978). Uterine contractility was expressed by the frequency (counts/min) of electrical activity with an amplitude of more than $30 \mu \mathrm{V}$.

Intrauterine administration of PGF-2a and acetylcholine. PGF- $2 \alpha(1 \mu \mathrm{g} / \mathrm{hen}$; Ono Pharmaceutical Co., Osaka, Japan) was placed in the uterus by inserting a polyethylene catheter (o.d. $1.0 \mathrm{~mm}$; i.d. $0.8 \mathrm{~mm}$ ) through the vagina 23 , $2 \mathrm{l}, 16,8$ or $4 \mathrm{~h}$ before predicted oviposition of the 2 nd or $3 \mathrm{rd}$ egg of a sequence in the experimental hens. Acetylcholine (10 mg/hen; Dai-ichi Sei-yaku Pharmaceutical Co., Tokyo, Japan) was similarly administered into the uterus. PGF-2 $\alpha$ was dissolved in $95 \%$ ethanol and diluted to the final concentration of PGF- $2 \alpha$ in $1 \%$ ethanol as described previously (Shimada \& Asai, 1979) and acetylcholine was diluted in saline $(9 \mathrm{~g} \mathrm{NaCl} / 1)$ solution. A total volume of $1.0 \mathrm{ml}$ was injected. Control hens for both groups received an injection of saline solution.

Palpation of the uterus. An index finger was inserted through the vagina of a hen and the uterus was palpated for 2 min. Palpation was performed $4 \mathrm{~h}$ after oviposition (or $21 \mathrm{~h}$ before the next oviposition).

Plasma collection. About 30 min before the injection of PGF-2 $\alpha$ and acetylcholine into the uterus, the brachial vein was catheterized under local anaesthesia (procaine, $0.5 \mathrm{mg}$, s.c.; Dai-ichi Sei-yaku Pharmaceutical Co.). Then hens were kept in an acrylic cage, serial blood samples were collected, and the plasma stored as described previously (Shimada et al., 1986). A blood sample ( $1.5 \mathrm{ml}$ ) was obtained for determination of plasma concentrations of immunoreactive arginine vasotocin and PGF 10 min before intrauterine administration of PGF-2 $\alpha$, acetylcholine or vehicle solutions. This time corresponded to about $15 \mathrm{~min}$ before induced oviposition. A second plasma sample was collected immediately after induced oviposition $(t=0)$. In control hens, which did not prematurely lay eggs, a second blood sample was collected $5 \mathrm{~min}$ after intrauterine administration of the test solution $(t=0)$. Three additional plasma samples were collected at 5-min intervals. In relation to spontaneous oviposition of a mid-sequence egg, the brachial vein was catheterized $2 \mathrm{~h}$ before oviposition and blood was collected $1 \mathrm{~h}$ before oviposition and immediately after oviposition. The subsequent plasma samples were collected from the largest and 2 nd largest preovulatory follicles by venepuncture using a microcapillary tube in the anaesthetized hens as described previously (Shimada et al., 1984). Plasma samples were stored at $-20^{\circ} \mathrm{C}$ until analysed.

Radioimmunoassay of plasma concentrations of arginine vasotocin and PGF. Plasma samples $(0.5 \mathrm{ml}$ for arginine vasotocin and $0.2 \mathrm{ml}$ for PGF) were thawed at room temperature. Arginine vasotocin was extracted from plasma using octadecasylil-silica cartridges (Sep-Pak C18, Waters Assoc., Milford, MA, U.S.A.) by procedures described by Shimada et al. (1986). Concentrations were measured in duplicate by radioimmunoassay (RIA) using synthetic arginine vasotocin as standard (Bachem Inc., Torrance, CA, U.S.A.) and an antiserum (R70) raised in rabbits to arginine vasotocin by Dr D. Fisher. Synthetic arginine vasotocin was assayed by Dr W. H. Sawyer and had a rat pressor potency of $191 \mathrm{U} / \mathrm{mg}$. The minimum amount of arginine vasotocin detected in the assay was $0.07 \mu \mathrm{U} /$ tube and recovery of known amounts of arginine vasotocin from hen plasma averaged $76 \cdot 8 \pm 5.9 \%$. The vasotocin concentrations were measured in a single assay and the intra-assay coefficient of variation (CV) was $9 \cdot 5 \%$.

Extraction of PGF of plasma samples was conducted as previously described (Shimada et al., 1984; Saito et al., 1987). Prostaglandin F was measured in duplicate by an RIA using PGF-2 $\alpha$ as standard (Ono Pharmaceutical Co., Osaka). The RIA for PGF was performed as described by Evans et al. (1981) and Olson et al. (1984) using PGF-2 $\alpha$ antiserum raised in rabbits by Dr T. G. Kennedy. The cross-reactivities of the antiserum to PGF-2 $\alpha$ have been described by Evans et al. (1981) and Olson et al. (1984). Since the antiserum binds with both PGF-2 $\alpha$ and PGF-1 $\alpha$ to the same degree, PGF designated here may contain both PGF-2 $\alpha$ and PGF-1 $\alpha$. The minimum detectable level was $7.0 \mathrm{pg} /$ tube. The recovery of PGF was $72.9 \pm 2.8 \%$. All samples were measured in a single assay and the intra-assay CV was $11 \cdot 2 \%$.

Statistics. Data are presented as means \pm s.e.m. and were statistically analysed by a one-way analysis of variance. When a significant $F$ value was found, the mean separation was achieved using Duncan's New Multiple Range test. The differences were considered significant at the level of $P<0.05$. 


\section{Results}

Effects of administration of PGF-2a on oviposition, uterine contractility and plasma arginine vasotocin and $P G F$ concentrations

The effects of intrauterine administration of PGF- $2 \alpha$ on the induction and timing of premature oviposition and on the changes in plasma arginine vasotocin concentrations are summarized in Table 1 and Fig. 1, respectively. Since basal concentrations of plasma arginine vasotocin before PGF- $2 \alpha$ administration (preinjection values) varied during the oviposition cycle from 0.7 to $3.6 \mu \mathrm{U} / \mathrm{ml}$, the data were expressed as percentage increase of arginine vasotocin levels after injections. When there was no egg in the uterus 23 and $21 \mathrm{~h}$ before the predicted oviposition (or 2 and $4 \mathrm{~h}$ after oviposition of the previous egg) neither premature oviposition nor an increase in arginine vasotocin concentration occurred after PGF-2 $\alpha$ injection (Figs la, b). The incidence of oviposition was essentially the same (83-86\%) when PGF- $2 \alpha$ was injected between 16 and $4 \mathrm{~h}$ before predicted oviposition (Table 1). The time that was required to induce premature oviposition was greater

Table 1. Premature oviposition induced in the hen by intrauterine administration of PGF- $2 \alpha$ and acetylcholine

\begin{tabular}{|c|c|c|c|c|}
\hline $\begin{array}{l}\text { Compound } \\
\text { (dose) }\end{array}$ & $\begin{array}{l}\text { Time before } \\
\text { expected } \\
\text { oviposition } \\
\text { (h) }\end{array}$ & $\begin{array}{l}\text { No. of } \\
\text { tests }\end{array}$ & $\begin{array}{l}\text { No. of } \\
\text { ovipositions } \\
(\%)\end{array}$ & $\begin{array}{l}\text { Induction } \\
\text { time } \\
\text { (min) }\end{array}$ \\
\hline $\begin{array}{r}\text { PGF-2 } \alpha \\
(1 \mu \mathrm{g})\end{array}$ & $\begin{array}{r}23 \\
21 \\
16 \\
8 \\
4\end{array}$ & $\begin{array}{l}6 \\
6 \\
6 \\
7 \\
6\end{array}$ & $\begin{array}{lr}0 & (0) \\
0 & (0) \\
5 & (83) \\
6 & (86) \\
5 & (83)\end{array}$ & $\begin{array}{l}- \\
5 \cdot 6 \\
4 \cdot 3 \\
4 \cdot 2\end{array}$ \\
\hline $\begin{array}{l}\text { Acetylcholine } \\
\quad(10 \mathrm{mg})\end{array}$ & $\begin{array}{r}21 \\
4\end{array}$ & $\begin{array}{l}5 \\
6\end{array}$ & $\begin{array}{l}0 \quad(0) \\
6(100)\end{array}$ & $\overline{9 \cdot 2}$ \\
\hline
\end{tabular}
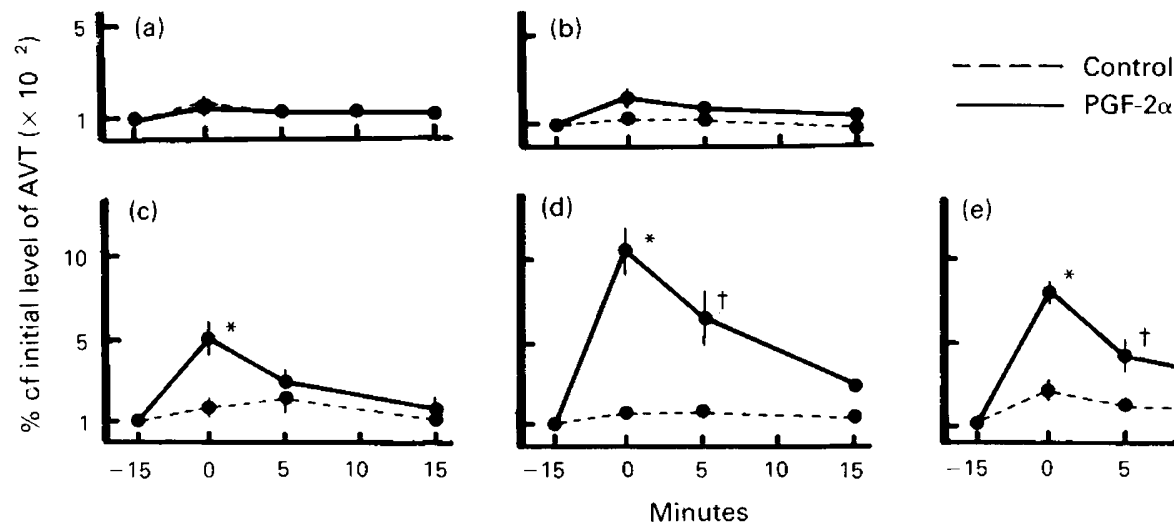

Fig. 1. Changes in plasma arginine vasotocin (AVT) concentrations in response to intrauterine injections of PGF-2 $\alpha$ at different times during the oviposition cycle at (a) 23, (b) 21, (c) 16, (d) 8 and (e) $4 \mathrm{~h}$ before predicted oviposition. Time 0 refers to the PGF-2 $\alpha$-induced oviposition or 5 min after saline injection in the control group and in the treated group when there was no induced oviposition. ${ }^{*}$ and $\dagger$ indicate significant difference from control values at corresponding times at $P<0.01$ and $P<0.05$, respectively. Values are mean \pm s.e.m. for 5-6 hens. 
when PGF- $2 \alpha$ was administered $16 \mathrm{~h}$ before the predicted oviposition than when injections were made closer to the predicted time.

Premature oviposition was associated with increases in plasma arginine vasotocin concentrations (Figs 1c-e). The magnitude of the changes in plasma arginine vasotocin values that was observed when PGF-2 $\alpha$ was injected $16 \mathrm{~h}$ before the predicted oviposition was significantly lower than the hormone responses which occurred 8 and $4 \mathrm{~h}$ before the predicted oviposition $(P<0.01)$. Neither premature oviposition nor increases in plasma arginine vasotocin levels was observed after the injection of vehicle during the oviposition cycle. There was no change in plasma PGF concentrations after the intrauterine administrations of PGF- $2 \alpha$ or vehicle solution at any time during the oviposition cycle (data not shown).

\section{Effects of administration of acetylcholine}

Premature oviposition was induced when acetylcholine was placed in the uterus $4 \mathrm{~h}$, but not $21 \mathrm{~h}$, before the predicted oviposition (Table 1). However, the induction time for oviposition was considerably longer than that after PGF- $2 \alpha$ injection. Acetylcholine caused significant increases in plasma arginine vasotocin levels only when premature oviposition was induced, i.e. when acetylcholine was given $4 \mathrm{~h}$ before the predicted oviposition (Fig. 2b). Changes in arginine vasotocin levels were not observed after the injection of vehicle solution irrespective of the time of injection relative to the oviposition cycle. Likewise, no change in plasma PGF concentrations was found after acetylcholine injection at $21 \mathrm{~h}$ before predicted oviposition (Fig. 2a) but a significant increase was observed in response to premature oviposition $4 \mathrm{~h}$ before predicted oviposition (Fig. 2b).
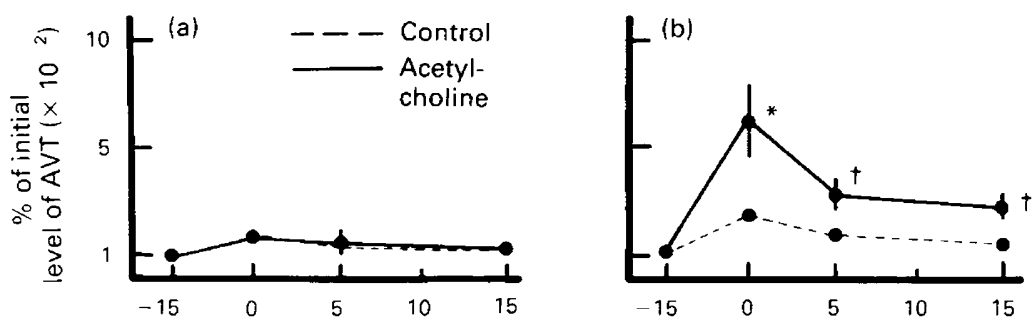

Minutes

Fig. 2. Changes in plasma arginine vasotocin in response to intrauterine injections of acetylcholine at (a) 21 and (b) $4 \mathrm{~h}$ before predicted oviposition. Time 0 refers to the acetylcholineinduced oviposition or $5 \mathrm{~min}$ after saline injection in the control group and in the treated group when there was no induced oviposition. ${ }^{*}$ and + indicate significant difference from control values at corresponding times at $P<0.01$ and $P<0.05$, respectively. Values are mean \pm s.e.m. for 4-5 hens.

\section{Plasma concentrations of $P G F$ and arginine vasotocin at expected oviposition}

A marked 3-fold increase in uterine contractility (20-25 per min) occurred at the expected time of oviposition after PGF- $2 \alpha$ - and acetylcholine-induced expulsion of the egg $4 \mathrm{~h}$ earlier. Coincident with this increase in contractility, marked increases in the concentrations of PGF and arginine vasotocin in plasma were also observed despite the absence of an egg in the uterus (Fig. 3).

\section{Palpation of the uterus}

Digital palpation of the uterus was accompanied by defaecation and an increase in the depth of respiration. Uterine contractility was higher $(10-15 / \mathrm{min})$ immediately after than before palpation 


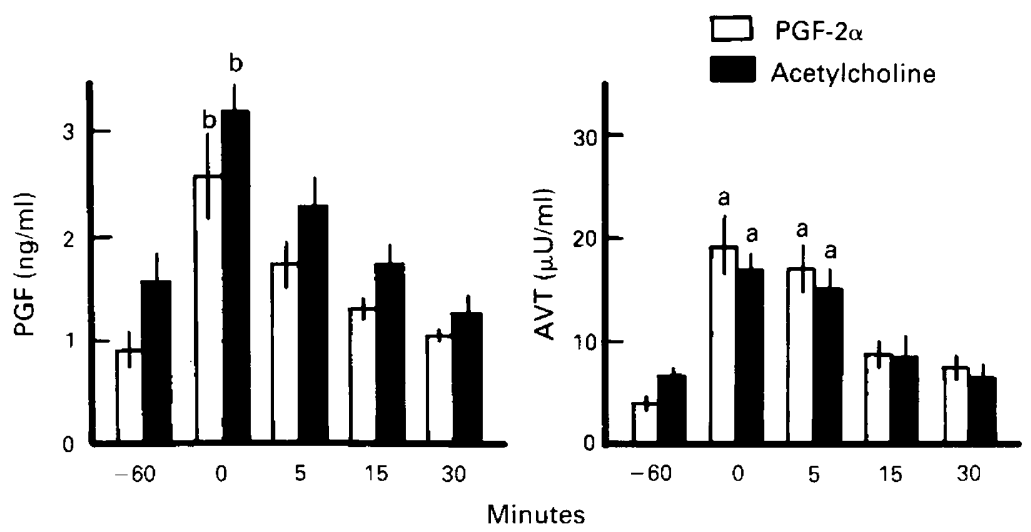

Fig. 3. Plasma PGF and arginine vasotocin (AVT) concentrations in relation to expected time of oviposition after PGF-2 $\alpha$-or acetylcholine-induced premature oviposition. Time 0 refers to the peak of uterine contractility at the expected oviposition which occurred $4 \mathrm{~h}$ after PGF- $2 \alpha$ or acetylcholine injection. (a, b) Within the group, indicates significant difference from values $60 \mathrm{~min}$ before expected oviposition at $P<0.01$ and $P<0.05$, respectively. Values are mean \pm s.e.m. for $4-5$ hens.

(1-3/min). The concentration of arginine vasotocin increased from $3 \cdot 1 \pm 0 \cdot 35 \mu \mathrm{U} / \mathrm{ml} 10 \mathrm{~min}$ before palpation to $6.2 \pm 0.68 \mu \mathrm{U} / \mathrm{ml}$ immediately after the end of 2 -min palpation $(P<0.01)$. Hormone concentrations returned to prestimulation levels by $5 \mathrm{~min}(3.6 \pm 1.00 \mu \mathrm{U} / \mathrm{ml})$ and remained at low levels $15 \mathrm{~min}$ after the palpation $(3 \cdot 8 \pm 0.45 \mu \mathrm{U} / \mathrm{ml})$.

\section{$P G F$ and arginine vasotocin in follicular venous plasma}

The concentrations of both substances increased in peripheral plasma at oviposition when compared to hormone concentrations $1 \mathrm{~h}$ before oviposition $(P<0.01$; Table 2$)$. In addition, the concentrations of PGF in venous plasma for the F1 and F2 follicles were about 17 and 3 times greater, respectively, compared to values in peripheral plasma at oviposition $(P<0.01)$. In contrast, arginine vasotocin levels in follicular venous plasma were lower than in peripheral plasma at oviposition. The concentration of arginine vasotocin in $\mathrm{F} 1$ and $\mathrm{F} 2$ venous plasma were $77 \%$ and $62 \%(P<0.01)$ of the peripheral mean values, respectively.

Table 2. Concentrations of arginine vasotocin and PGF in plasma from the brachial vein and from the vein draining the largest and second largest preovulatory follicles

\begin{tabular}{|c|c|c|c|c|}
\hline & \multirow{2}{*}{$\begin{array}{c}1 \mathrm{~h} \text { before } \\
\text { oviposition }\end{array}$} & \multicolumn{3}{|c|}{ Immediately after oviposition } \\
\hline & & Brachial & $\begin{array}{l}\text { Largest } \\
\text { preovulatory } \\
\text { follicle }\end{array}$ & $\begin{array}{l}\text { 2nd largest } \\
\text { preovulatory } \\
\text { follicle }\end{array}$ \\
\hline $\begin{array}{l}\text { PGF (ng/ml) } \\
\text { Arginine }\end{array}$ & $0.65 \pm 0.07$ & $1.90 \pm 0.20$ & $32 \cdot 9 \pm 14 \cdot 67$ & $5 \cdot 16 \pm 0 \cdot 91$ \\
\hline vasotocin $(\mu \mathrm{U} / \mathrm{ml})$ & $1.3 \pm 0.33$ & $24.5 \pm 1.80$ & $18.9 \pm 2.48$ & $15 \cdot 3 \pm 0.85$ \\
\hline
\end{tabular}

Values are mean \pm s.e.m. for 4 hens. 

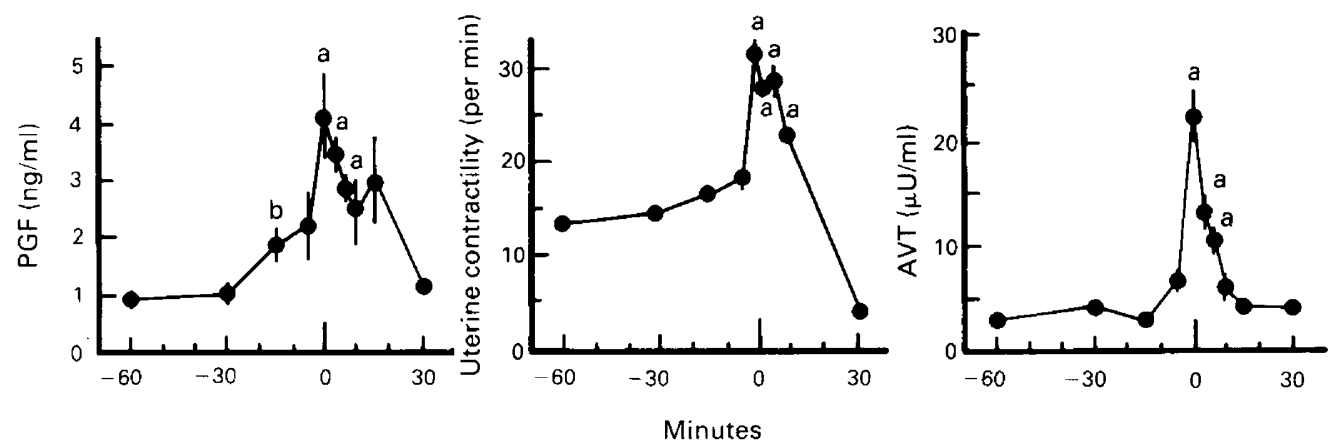

Fig. 4. Uterine contractility and plasma concentrations of PGF and arginine vasotocin (AVT) in relation to spontaneous oviposition (time 0$)$. $(a, b)$ Significant difference from levels at 60 and $30 \mathrm{~min}$ before oviposition at $P<0.01$ and $P<0.05$, respectively. Values are mean \pm s.e.m. for 3-7 hens.

\section{Spontaneous oviposition}

The changes in uterine contractility and concentrations of PGF and arginine vasotocin in peripheral plasma that were observed in relation to spontaneous oviposition are summarized in Fig. 4. A significant increase was observed in PGF values $15 \mathrm{~min}$ before spontaneous oviposition $(P<0.05)$ whereas there were no increases in arginine vasotocin levels at this time. Concurrent increases in PGF and arginine vasotocin levels and uterine contractility occurred at the time of oviposition. All three parameters declined to preoviposition levels within $30 \mathrm{~min}$.

\section{Discussion}

The present study confirmed our previous finding (Shimada et al., 1986) that premature oviposition, induced by intrauterine administration of PGF-2 $\alpha$, or injection of acetylcholine causes a marked increase in plasma arginine vasotocin concentration, although Sturkie \& Lin (1966) did not show the neurohypophysial response to premature oviposition induced by acetylcholine injection. In contrast, the same doses of PGF- $2 \alpha$ or acetylcholine are ineffective in releasing arginine vasotocin when there is no egg in the uterus. This difference might be attributable, at least in part, to differences in the magnitude of uterine contractility. When the uterus does not contain an egg, the contractile response to PGF- $2 \alpha$ is lower than when an egg is present (Shimada \& Asai, 1979).

In addition, the arginine vasotocin response during premature oviposition $16 \mathrm{~h}$ before predicted oviposition was lower when compared to the responses 8 and $4 \mathrm{~h}$ before predicted oviposition (Figs $1 \mathrm{c}-\mathrm{e}$ ). This difference could be related to the lower intensity of uterine contractility in the presence of a soft-shelled egg which also results in a lengthening of the time required to induce premature oviposition (Table 1). These results indicate that arginine vasotocin release under these conditions may be a graded, rather than all-or-none, response. Since changes in plasma PGF concentrations are not observed after intrauterine injection of PGF- $2 \alpha$, it seems unlikely that arginine vasotocin release during premature oviposition is caused by circulating PGF- $2 \alpha$ that is released from the uterus. The mechanism which results in the release of arginine vasotocin remains unclear.

We did not take blood samples for 4-5 min between the time of injection and premature oviposition since it may interfere with the process of oviposition. It is possible that digital palpation of the uterus itself may have caused arginine vasotocin release. Indeed, palpation of the uterus for 2 min caused arginine vasotocin release even though there was no egg in the uterus but the increase in plasma concentration was only 2-fold and transient when compared to that of premature oviposition. This suggests that arginine vasotocin may be released by stimuli which cause an increase in 
uterine contractility. At the time of expected oviposition or during the preovulatory period of the first ovulation of a sequence, there is no egg in the uterus. In these situations marked increases in uterine contractility are observable with concurrent increases in plasma concentrations of PGF and arginine vasotocin (Shimada et al., 1984, 1986; present study). These results suggest that the presence of an egg in the uterus is not obligatory for release of oxytocic hormones at oviposition.

In mammals, large amounts of neurohypophysial hormones are found in the ovary (Wathes, 1984). Neural lobe peptides could also be present in the avian ovary. However, it seems unlikely that the preovulatory follicles contribute significantly to the increase in arginine vasotocin levels in peripheral plasma at oviposition since the concentration of arginine vasotocin in follicular venous plasma is lower than in peripheral plasma (Table 2). In contrast, the marked rise in PGF in peripheral plasma at oviposition is due, in part, to the release of PGF- $2 \alpha$ from the largest preovulatory follicle (Table 2; Olson et al., 1986; Saito et al., 1987).

We suggest that ovarian PGF is causally related to an increase in uterine contractility which in turn initiates the release of arginine vasotocin. The increase in circulating arginine vasotocin provides an additional contractile stimulus for the uterus during oviposition. Sensory inputs from the uterus to the arginine vasotocin system have not been described for chickens but could be neural or humoral. Additional studies are needed to characterize the link between the uterus and the hypothalamus.

We thank Dr H. Artman and Dr D. A. Fisher (UCLA, Torrance, CA, U.S.A.) for the arginine vasotocin antiserum (R70); Dr W. H. Sawyer (University of Columbia, New York, U.S.A.) for bioassays of the standards; and Dr T. G. Kennedy (MRC Group of Reproductive Biology, University of Western Ontario, London, Canada) for the PGF- $2 \alpha$ antiserum; Ono Pharmaceutical Co. (Osaka, Japan) for the gift of PGF-2 $\alpha$ standard; and Ms S. Kinzler and Mr H. L. Neldon for RIA of arginine vasotocin. This study was supported by Grants-in-aid from Ministry of Education, Science and Culture of Japan to K.S. (Nos 60304036, 61560301 and 61304028) and NSF PCM-8316015 to T.I.K.

\section{References}

Arad, Z. \& Skadhauge, E. (1984) Plasma hormone (arginine vasotocin, prolactin, aldosterone and corticosterone) in relation to hydration state, $\mathrm{NaCl}$ intake, and egg laying. J. exp. Zool. 232, 707-714.

Evans, C.A., Kennedy, T.G., Patrick, J.E. \& Challis, J.R.G. (1981) Uterine prostaglandin concentrations in sheep during late pregnancy and adrenocorticotropininduced labor. Endocrinology 109, 1533-1538.

Niezgoda, J., Rzasa, J. \& Ewy, Z. (1973) Changes in blood vasotocin activity during oviposition in the hen. J. Reprod. Fert. 35, 505-509.

Nouwen, E.T., Decuypere, E., Kuhn, E.R., Michels, H., Hall, T.R. \& Chadwick, A. (1984) Effect of dehydration, haemorrhage and oviposition on serum concentrations of vasotocin, mesotocin and prolactin in the chicken. J. Endocr. 102, 345-351.

Olson, D.M., Biellier, H.V. \& Hertelendy, F. (1978) Shell gland responsiveness to prostaglandin $\mathrm{F} 2 \alpha$ in relation to oviposition in the domestic hen (Gallus domesticus). Biol. Reprod. 24, 496-504.

Olson, D.M., Shimada, K. \& Etches, R.J. (1986) Prostaglandin concentrations in peripheral plasma, and ovarian and uterine plasma and tissue in relation to oviposition in hens. Biol. Reprod. 35 (in press).

Olson, D.M., Lye, S.J., Skinner, K. \& Challis, J.R.G.
(1984) Early changes in prostaglandin concentrations in ovine maternal and fetal plasma, amniotic fluid and from dispersed cells of intrauterine tissues before the onset of ACTH-induced pre-term labour. $J$. Reprod. Fert. 71, 45-55.

Opel, H. (1964) Premature oviposition following operative interference with the brain of the chicken. Endocrinology 74, 193-200.

Rothchild, I. \& Fraps, R.M. (1944) On the function of the ruptured ovarian follicle of the domestic fowl. Proc. Soc. exp. Biol. Med. 56, 79-82.

Rzasa, J. \& Ewy, Z. (1970) Effect of vasotocin and oxytocin on oviposition in the hen. J. Reprod. Fert. 21, 549-550.

Saito, N., Sato, K. \& Shimada, K. (1987) Prostaglandin levels in peripheral and follicular plasma, the isolated theca and granulosa layers of pre- and postovulatory follicles, and the myometrium and mucosa of the shell gland (uterus) during a mid-sequence oviposition cycle of the hen (Gallus domesticus). Biol. Reprod. 36 (in press).

Shimada, K. (1978) Electrical activity of the oviduct of the laying hen during egg transport. J. Reprod. Fert. 53, 223-230.

Shimada, K. (1981) The role of the ovarian follicles in 
uterine contraction associated with ovulation and oviposition. In Advances of Avian Endocrinology, Vol. 32, pp. 197-201. Eds G. Pethes, P. Peczely \& P. Rudas. Academiai Kiado, Budapest.

Shimada, K. \& Asai, I. (1978) Uterine contraction during the ovulatory cycle of the hen. Biol. Reprod. 19, 1057-1062.

Shimada, K. \& Asai, I. (1979) Effects of prostaglandin F $2 \alpha$ and indomethacin on uterine contraction in hens. Biol. Reprod. 21, 523-527.

Shimada, K., Olson, D.M. \& Etches, R.J. (1984) Follicular and uterine prostaglandin levels in relation to uterine contraction and the first ovulation of a sequence in the hen. Biol. Reprod. 31, 76-82.

Shimada, K., Neldon, H.L. \& Koike, T.I. (1986) Arginine vasotocin (AVT) release in relation to uterine contractility in the hen. Gen. comp. Endocr. 64, 362-367.

Sturkie, P.D. \& Lin, T. (1966) Release of vasotocin and oviposition in the hen. $J$. Endocr. 34, 325-326.
Tanaka, K. \& Nakada, T. (1974) Participation of the ovarian follicle in the control of the time oviposition in the domestic fowl. Poult. Sci. 53, 2120-2125.

Tanaka, K. \& Nakajo, S. (1962) Participation of neurohypophysial hormone in oviposition in the hen. Endocrinology 70, 453-458.

Tanaka, K., Goto, K., Yoshioka, T., Terao, T. \& Koga, O. (1984) Changes in the plasma concentration of immunoreactive arginine vasotocin during oviposition in the domestic fowl. Br. Poult. Sci. 25, 589-595.

Wathes, D.C. (1984) Review. Possible actions of gonadal oxytocin and vasopressin. J. Reprod. Fert. 71, $315-345$. 